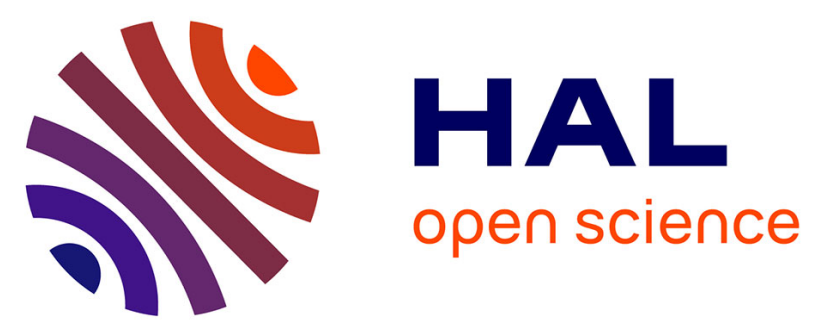

\title{
Towards Prospective Life Cycle Assessment: How to Identify Key Parameters Inducing Most Uncertainties in the Future? Application to Photovoltaic Systems Installed in Spain
}

Camille Marini, Isabelle Blanc

\section{To cite this version:}

Camille Marini, Isabelle Blanc. Towards Prospective Life Cycle Assessment: How to Identify Key Parameters Inducing Most Uncertainties in the Future? Application to Photovoltaic Systems Installed in Spain. 14th International Conference ICCSA 2014, Jun 2014, Guimarães, Portugal. pp.691-706 ISBN 978-3-319-09149-5, 10.1007/978-3-319-09150-1_51 . hal-01019873

\section{HAL Id: hal-01019873}

https: / hal-mines-paristech.archives-ouvertes.fr/hal-01019873

Submitted on 9 Jul 2014

HAL is a multi-disciplinary open access archive for the deposit and dissemination of scientific research documents, whether they are published or not. The documents may come from teaching and research institutions in France or abroad, or from public or private research centers.
L'archive ouverte pluridisciplinaire $\mathbf{H A L}$, est destinée au dépôt et à la diffusion de documents scientifiques de niveau recherche, publiés ou non, émanant des établissements d'enseignement et de recherche français ou étrangers, des laboratoires publics ou privés. 


\title{
Towards prospective Life Cycle Assessment: how to identify key parameters inducing most uncertainties in the future? Application to photovoltaic systems installed in Spain
}

\author{
Camille Marini ${ }^{1}$ and Isabelle Blanc ${ }^{1}$ \\ MINES ParisTech, O.I.E. center, Sophia Antipolis, France
}

\begin{abstract}
Prospective Life Cycle Assessment (LCA) is a relevant approach to assess the environmental performance of future energy pathways. Amongst different types of prospective scenarios, cornerstone scenarios meant for complex systems and long-term approaches, are of interest to assess such performance. They rely on different types of long-term projections, such as projections of technological evolutions and of energy resources. In most studies, scenarios are defined with single values for each parameter, and environmental impacts are assessed in a deterministic way. Inherent uncertainties related to these prospective assumptions are not considered and prospective LCA uncertainties are thus not addressed. In this paper we describe a methodology to account for these uncertainties and to identify the parameters inducing most of the uncertainties in the prospective LCA results. We apply this approach to prospective LCAs of photovoltaic-based electricity generation systems.
\end{abstract}

\section{Introduction}

World electricity consumption has multiplied by a factor of 4 in the last 40 years [18] and will keep increasing in the future due to population growth and changing lifestyle. Currently more than $68 \%$ of the total electricity production is based on fossil fuels [18. Yet the use of fossil fuels raises growing environmental concerns, since their reserves are decreasing and their use is responsible for significant greenhouse gas (GHG) emissions 17, largely contributing to global warming (e.g., [2]). Environmental assessments of energy pathways being a critical issue, a large number of Life Cycle Assessments (LCA) have been undertaken, attempting to give a quantitative assessment of the current situation for each pathway.

An important issue we are now facing is related to the future development of energy pathways and its associated uncertainty. Such development is linked to critical environmental, technological and economical issues. Each energy pathway will have to deal with major changes in the future, such as availability and rate of depletion of resources, globalization and energy source supply, evolution of the resource potential when considering renewable energies, or technological 
developments. Uncertainties associated with these key parameters are significant and inherent to the prospective nature of the assessment.

Running scenarios is essential when handling prospective assessments. It has been applied in numerous fields and extensive research work has been undertaken to develop scenario-based LCA models [31. Several types of scenarios can be distinguished depending on the purpose of the study [3]:

- Predictive scenarios, which answer the question "What will happen?" Predictive scenarios types are forecasts (the likely scenario occurs) and what-if (conditioned to some specific events). What-if scenarios are meant to be defined for simple objects and short-term studies.

- Explorative scenarios, which answer the question "What can happen?" They are external (related to exogenous conditions) and strategic (conditioned to some actions completed in a certain way). Cornerstone scenarios [31 are also defined as explorative scenarios and are meant for complex objects and long-term approaches.

- Normative scenarios, which answer the question "How can a specific target be reached?"

In our case, we are concerned by both predictive and explorative scenarios. Our goal is to assess the environmental performance of energy pathways, based on renewables and operating in 2050. Environmental performance is defined as the ratio of environmental impacts estimated by LCA to the electricity produced over the entire life cycle, corresponding to impacts per $\mathrm{kWh}$ produced. The prospective impacts depend on the future available technologies, more related to explorative scenarios. The prospective electricity production depends on future available energy resources (e.g., solar irradiation for photovoltaic systems, wind distribution for wind turbines), more related to predictive scenarios. The overall scenario needed to assess the prospective performance of energy pathways can be qualified as a cornerstone scenario 31, since it is partly explorative, meant for a long-term projection, and the considered system is complex.

In most studies, scenarios are defined with single values for each parameter over a predefined range of values and environmental impacts are assessed in a deterministic way. Inherent uncertainties related to these prospective assumptions are however not considered.

This paper describes a methodology to account for these uncertainties and to identify the key parameters inducing most of the uncertainties in these prospective performances. This methodology is based on the following steps:

1. Identification of the potential parameters to be considered (technological, geo-localization of the supply material, among others) for a given time horizon and a given area of energy production. Generation of a parametrized model of environmental performance based on these parameters.

2. Characterization of the parameter changes between the current and future situation. Definition of the uncertainties associated with future input parameter values. Different strategies to associate a distribution to these uncertainties are given. 
3. Generation of the distribution of future environmental performances by applying Monte-Carlo simulations. Comparison between current and prospective environmental performance.

4. Key parameters identification and ranking with a global sensitivity analysis (GSA) based on Sobol indices.

5. Discussion and recommendations on specific key parameters inducing most uncertainties in the performance.

This methodology is applied to assess prospective environmental performance related to GHG emissions of photovoltaic (PV) systems (CdTe technology) installed in the South of Spain in 2050, given our defined cornerstone scenario. This cornerstone scenario is based on projections of developments of PV technologies, market share, and solar irradiation. Following the methodology, we are able to identify the key parameters explaining most uncertainties in the prospective environmental performance. These key parameters need to be predicted with more accuracy than the others to reduce the results' uncertainties. However, some of these key parameters may be impossible to predict, such as the manufacturing market share. Identifying them as key parameters informs us that it is essential to consider and explore their different possible developments in order not to underestimate results' uncertainties.

\section{Methodology description}

\subsection{Definition of a parametrized LCA model}

We need to define as a first step a parametrized LCA model depending on a limited number of input parameters, to assess the prospective environmental performance of an electricity generation system based on renewable energy, and compare them to current performance. In this paper, the considered impacts are one dimensional, such as climate change impacts related to GHG emissions and expressed in grams of $\mathrm{CO}_{2}$ equivalent, leading to performance in $\mathrm{gCO}_{2} \mathrm{eq} / \mathrm{kWh}$. The following steps are to be taken to define this model :

1. Definition of the objective of the study and the boundaries of the considered system As in any LCA, this step is essential. The functional unit must be defined and the limits of the system made explicit. The technology considered, the geographical localization of the system, the temporal horizon (for which time horizon the prospective is made), and the methodology must be specified.

2. Identification of the input parameters of the parametrized model These parameters are assumed to be characteristic of the system and are likely to vary in the future. Their identification can be based on a literature review and/or discussions with experts. Their current values are known based on real observations, and their future values are predicted with more or less uncertainty. These $n$ parameters are denoted $x_{1}, \ldots, x_{n}$. They must be independent (requirement for computing Sobol indices, see Sect. 2.4); if 
not, dependency relations must be specified to obtain a set of independent parameters.

3. Definition of the parametrized impacts model

First a parametrized Life Cycle Inventory (LCI) is realized. For parameters not made explicit, data from a LCI database, such as EcoInvent [9], are used. This parametrized LCI is converted into a parametrized LCA model by using the characterization factors corresponding to the considered impacts. This model is denoted $f i\left(x_{1}, \ldots, x_{n}\right)$.

4. Definition of a parametrized model of electricity generation It estimates the electricity produced by the system over its entire production phase, and it is denoted $f e\left(x_{1}, \ldots x_{n}\right)$.

5. Definition of a parametrized model of environmental performance It is obtained by combining the parametrized impacts and electricity generation models: $f p\left(x_{1}, \ldots, x_{n}\right)=\frac{f i\left(x_{1}, \ldots, x_{n}\right)}{f e\left(x_{1}, \ldots, x_{n}\right)}$.

These steps to define a parametrized LCA model have already been implemented by Padey et al (2013) [30] to assess the variability of an energy pathway.

\subsection{Characterization of the parameters changes between the current and future situation and their future uncertainties}

The current values $x_{1}^{t 0}, \ldots, x_{n}^{t 0}$ of the input parameters, and predicted future values $x_{1}^{t 1}, \ldots x_{n}^{t 1}$ must be identified, in order to apply the parametrized model $f p$ and assess the current and future environmental performance.

Uncertainties consideration is a big issue in LCA. Uncertainties can affect different modeling components, the parameters, scenarios, and models; they can occur at different stages of the analysis, during the goal and scope definition, the inventory analysis, and the impact assessment; and they can have various sources (e.g., [12]). In this paper, we focus on future input parameter uncertainties, inherent to the prospective approach. We do not consider uncertainties for current input parameter values.

Uncertainties on future parameter values may be represented by considering these parameters as random variables, denoted $X_{1}, \ldots, X_{n}$, characterized by a distribution instead of a simple scalar value. Note that uncertainties distributions can be continuous (e.g., technology efficiency) or discrete (e.g., country of manufacture). Depending on the type of parameters and available sources of information, different strategies may be used to characterize uncertainty distributions (e.g., [12]):

Case 1 In the best case, projections of a parameter are provided with their associated uncertainty distribution. It is the case for parameters provided in the ecoSpold format 13 .

Case 2 If enough projections of a parameter can be found, a distribution can be estimated by distribution fitting. A statistical test can be used to check the validity of the fit, such as a Chi-square goodness-of-fit test, or a KolmogorovSmirnov test. 
Case 3 If the projection of a parameter is provided with qualitative information, the methodology defined by Weidema and Weismaes (1996) [40] based on the Pedigree matrix and Data Quality Indicators can be applied.

Case 4 If projections of a parameter are provided for several different scenarios, values for extreme scenarios may be used to define the uncertainty range, and depending on the likelihood, different types of distribution can be used. For instance, if there are 3 scenarios, a pessimistic, a realistic, and an optimistic, a normal or lognormal distribution may be used, with a median equal to the value provided in the realistic scenario, and a $99 \%$ confidence interval bounded by the values provided in the pessimistic and optimistic scenarios 1. This strategy allows to transform a set of deterministic projections into an probabilistic projection associated to a distribution.

Case 5 For decadal projections of climate resources based on climate models, projections from different models can be used to represent the range of possibilities, assuming that most uncertainty is attributed to the model uncertainty 38 .

Case 6 In the worst case, the projection of a parameter is provided without any other information. If it is physically plausible, the uncertainties distribution could be assumed as normal, centered on the prospective value with an $99 \%$ lower bound equal to the current parameter value.

\subsection{Comparison between current and prospective environmental performances}

Current and prospective performances are computed with the parametrized model defined in Sec. 2.1 applied to current and prospective input parameters values given in Sec. 2.2. The distribution of prospective performances is obtained with Monte Carlo simulations.

\subsection{Identification of parameters inducing most uncertainties in the prospective environmental performance}

We assume that we know the uncertainties' distribution of each input parameter. The performance becomes a random variable, denoted $Y=f p\left(X_{1}, \ldots, X_{n}\right)$. Using Sobol sensitivity indices [37, it is possible to identify input parameters inducing most variability in the results, in our case it corresponds to parameters whose uncertainties induce most uncertainties in the performance.

More precisely, the contribution of the input parameter $X_{i}$ to the total variance is quantified with the first order Sobol index, defined as:

$$
S_{i}=\frac{\operatorname{Var}\left(E\left(Y / X_{i}\right)\right)}{\operatorname{Var}(Y)}
$$

\footnotetext{
${ }^{1}$ A lognormal distribution can be used for asymmetric distributions, and normal for symmetric distributions. For a normal distribution with median $\mu$ and standard deviation $\sigma, 99 \%$ of values are found within $[\mu-3 \sigma ; \mu+3 \sigma]$. For a lognormal distribution with median $\mu^{*}$ and geometric standard deviation $\sigma^{*}, 99 \%$ of values are found within $\left[\mu^{*} / \sigma^{* 3} ; \mu^{*} * \sigma^{* 3}\right]$.
} 
where $V a r$ is the variance. The definition of Sobol indices is based on variance decomposition and requires the independence of the input parameters $X_{1}, \ldots X_{n}$. The first order Sobol indices can be computed using Monte Carlo simulations. The brute force method would be, for each input parameter $X_{i}$, to run a set of $M$ Monte Carlo simulations to estimate $E\left(Y / X_{i}\right)$ for a fixed value of $X_{i}$ and then repeat the procedure for different values of $X_{i}$, leading to a total cost of $M^{2}$ (with $M$ being large). Saltelli (2012) 35] proposed a faster procedure, requiring $M(n+2)$ runs ( $n$ being the number of input parameters).

Sobol indices have already been used in LCA of energy systems by Padey et al. (2013) [30, not to identify parameters inducing most performance uncertainties, but to identify parameters inducing most performance variability due to the variability of systems within one energy pathway.

\section{Methodology application}

We apply the methodology described above to a residential building-integrated PV system, whose characteristics are given below. Although realistic, this application is simplified. The performance model could be refined by taking into account more input parameters, as detailed below in the boundaries of the system and in the assumptions made when identifying the input parameters of the parametrized model.

\subsection{Definition of the parametrized LCA model}

Definition of the objective and boundaries of the study

Objective: Assess the current and prospective global warming performance in $\overline{\mathrm{gCO}_{2} \mathrm{eq} / \mathrm{k}} \mathrm{Wh}$ of a residential PV system with the following characteristics:

- Technology: building-integrated system based on the CdTe technology and with a peak power $P$ of $3 k W p$.

- Geographical: system installed in the South of Spain at a latitude of $37^{\circ} \mathrm{N}$ and a longitude of $5^{\circ} \mathrm{W}$. The PV panel faces due South and is inclined at an angle equal to the latitude $\left(37^{\circ} \mathrm{N}\right.$ in our case).

- Temporal: The prospective time horizon is 2050.

- Methodology: Except for input parameters, data come from the ecoinvent v2.2 database [23. The characterization factor to assess the global warming impact is from IPCC 2007 with a time horizon of 100 years [19].

Boundaries: The manufacturing and production phase of the panel are considered. As stated above, it is a simplified application; so for the sake of simplicity, we do not consider the end-of-life phase and we omit the impacts related to transportation. Although transportation has been shown to have secondary effects (e.g., [1]), it should be taken into account in a more detailed study. 
Identification of the input parameters of the parametrized model A literature review mostly based on [7, [10, 23, 26], 20], and [14] led us to the identification of the following parameters:

- Life-time of the PV system (technological parameter), denoted $L T$ and expressed in years $(y r)$.

- Efficiency of the module (technological parameter), denoted $\eta$ and expressed in percentage.

- CdTe layer thickness in the PV cell (technological parameter), denoted $e$ and expressed in $\mu m$.

- Material utilization rate to produce the CdTe layer (technological parameter), denoted $U$ and expressed in percentage. It corresponds to the utilisation rate of $\mathrm{CdTe}$ in the manufacturing process of the cell.

- Performance ratio (technological parameter), denoted $P R$ and expressed in percentage. It corresponds to a correction factor to consider deviation from ideal conditions (dust, shadowing effects,...).

- Module manufacturing origin (parameter related to the supply chain).

- Electricity mixes in the manufacturing countries (parameter related to the supply chain).

- Irradiation, denoted $I r$ and expressed in $\mathrm{kWh} /\left(\mathrm{m}^{2} . \mathrm{yr}\right)$. It corresponds to the yearly irradiation taking into account the orientation and the tilt of the PV panel.

Figure 1 summarizes the relations between the identified characteristic parameters and the considered system. The surface $S$ of the panel depends on the peak power $P$ and the efficiency $\eta$ of the module with $S=\frac{P}{\eta}$. The CdTe layer thickness $e$ and the material utilisation rate $U$ determine the mass of CdTe necessary for the production of $1 m^{2}$ of module: $m_{C d T e}=\frac{e \mu_{\mathrm{CdTe}}}{U}$, with $\mu_{\mathrm{CdTe}}=6200 \mathrm{~kg} / \mathrm{m}^{3}$ being the density of semiconductor in the layer [26].

The following assumptions are made :

- Two inverters are used over the life-cycle, independently of the life-time of the system. It is the current situation, since the mean life-times of inverters and PV panel are, respectively, 15 and $30 \mathrm{yr}$. It thus assumes that these life-times will evolve in parallel, which is a realistic assumption according to experts $(20])$.

- No module degradation is considered, this should be incorporated in a more realistic study.

- The electricity consumption during production processes is considered constant, since no prospective values could be found. This should be modified for a more realistic study.

\section{Specification of the parametrized impacts model}

The model is built with the help of Simapro software. It is based on ecoinvent data v2.2 23] for the processes "Photovoltaic laminate CdTe/DE", "inverter 


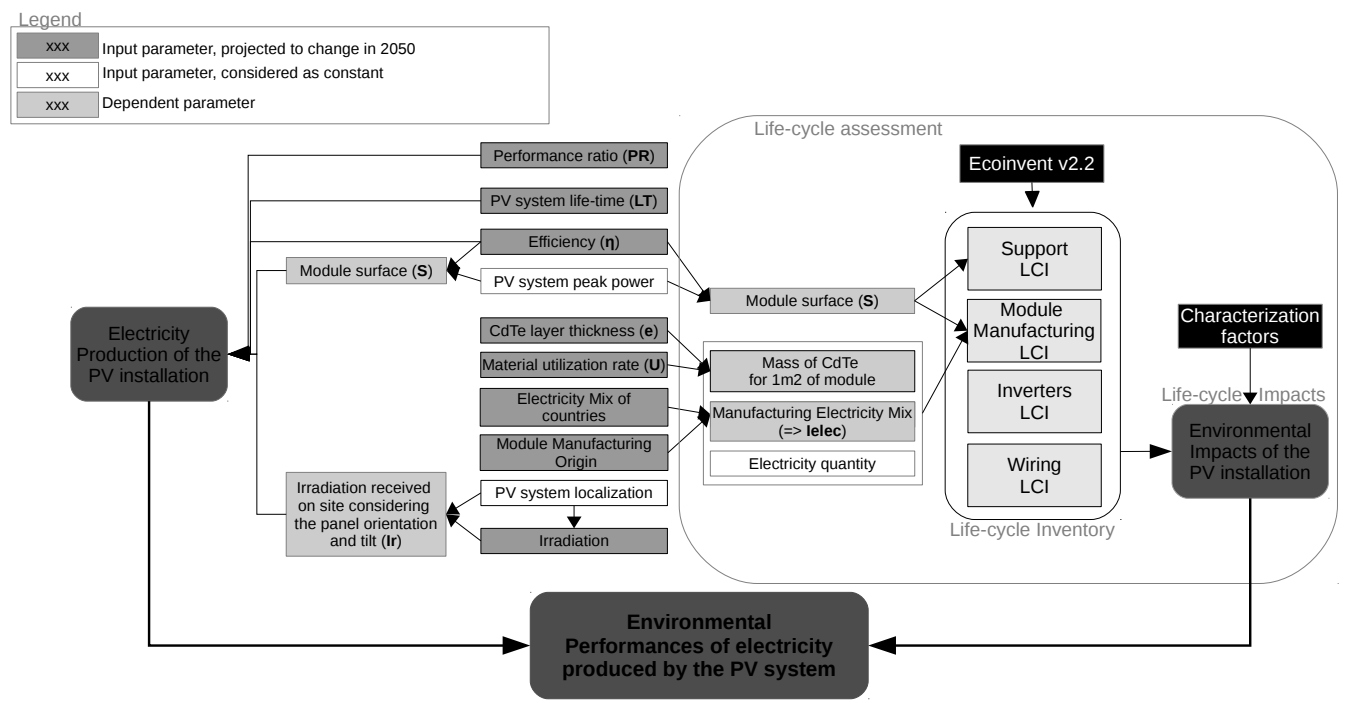

Fig. 1. Simplified parametrized model of the global warming performance for a residential PV panel based on the CdTe technology.

2500W at plant/RER", "Slanted-Roof construction, integrated", and "electric installation photovoltaic plant, at plant/CH" that we parametrize as a function of the input parameters. Impacts are then obtained by combining these data with characterization factors from IPCC 2007 with a time horizon of 100 years [19]. The resulting parametrized model for the impacts is specified in Appendix 4.

\section{Specification of the parametrized model of electricity generation}

The electricity produced over the life cycle is based on the yearly mean production:

$$
f e(\mathbf{L T}, \mathbf{P R}, \mathbf{I r})=\text { LT.PR.Ir. } \boldsymbol{\eta} . S=\text { LT.PR.Ir.P }
$$

where LT, PR, Ir, $\boldsymbol{\eta}, S$ and $P$ are, respectively, the panel life-time, the performance ratio, the irradiation, the efficiency, the panel surface and the peak power, defined in Sec. 3.1 (bold letters indicate varying parameters).

\section{Specification of the parametrized performance model}

The global warming performance model is obtained by combining the parametrized impacts model (specified in Appendix 4) and the parametrized model of electricity generation defined in $(2)$ :

$$
f p(\boldsymbol{\eta}, \mathbf{e}, \mathbf{U}, \text { Ielec, } \mathbf{L T}, \mathbf{P R}, \mathbf{I r})=\frac{f i(\boldsymbol{\eta}, \mathbf{e}, \mathbf{U}, \text { Ielec })}{f e(\mathbf{L T}, \mathbf{P R}, \mathbf{I r})}
$$

This model was implemented in the Python programming language. 


\subsection{Characterization of parameter changes between the current and future situation and their future uncertainties}

The definition of the future situation, identified as a cornerstone scenario, requires the characterization of uncertainties' distributions of input parameters. This characterization is made using the different strategies summarized in Sec. 2.2 ,

Values for "life-time", "module efficiency", and "CdTe layer thickness" come from [20. In this study, 3 scenarios are defined: a pessimistic one with limited improvements, a realistic scenario with reasonable improvements, and an optimistic scenario using the best available predictions for parameters identified as key for the CdTe technology. We derive a probability distribution for these parameters based on the values given for the 3 scenarios, as explained in Case 4 of Sec. 2.2,

Values and uncertainty range for the "material utilization rate" are similarly derived from [26] (Case 4 of Sec. 2.2).

Current and prospective values (for 2030 and not 2050) for the "performance ratio" were extracted from [7, but no uncertainty range could be found. The lower bound of the confidence interval is thus assumed equal to the current value, and a normal distribution with a median equal to the prospective value (Case 6 of Sec. 2.2. .

Currently, module manufacturing is shared between Germany (22\%), the USA (12\%), and Malaysia (65\%) 6]. No prospective data about module manufacturing countries could be found, as it is almost impossible to predict such parameter at such lead time. It is fundamentally associated to financial markets, regulating policies, economic measures, with time scales shorter than a decade. We thus explore 3 possibilities with equal probability: a share identical to the current situation, an occidental share (50\% Germany and 50\% USA), and an Asian share (50\% Malaysia and 50\% China).

Current estimates of the irradiation are derived from MERRA reanalysis 34. This dataset results from a combination of climate model fields and irregular observations in space and time, from 1979 to the present (satellite-area), using data assimilation. Monthly estimates of surface incident shortwave flux at a latitude of $37^{\circ} \mathrm{N}$ and a longitude of $5^{\circ} \mathrm{W}$ are converted into global tilted irradiation considering that the panel faces South and is inclined at an angle equal to the latitude (see 4 for more details). The mean for the 1985-2013 period is used as the current value for irradiation.

The percentage variation of irradiation between the present and the future situation (i.e. for a panel operating from 2050 to 2080 on average) is derived from regional climate model (RCM) simulations for the period 1950-2100 with a "moderate" emissions scenario (scenario A1B, [19), part of the ENSEMBLE-RT2B database [5]. Contrary to MERRA data, no observations are incorporated in these simulations, they aim at modeling climate tendency, and not at providing accurate predictions for a given year, consistent with a cornerstone scenario. We use simulations from 4 different RCMs: C4I from the Swedish meteorological service [22, KNMI from the Dutch meteorological service [39], MPI from the 
Table 1. Current and prospective values of considered LCI parameters, as well as their associated uncertainties range (99\% confidence interval). Note that no uncertainties are considered for future electricity mixes of manufacturing countries.

\begin{tabular}{|c|c|c|c|c|}
\hline Parameter & \multicolumn{2}{|l|}{ Current LCI } & \multicolumn{2}{|l|}{ Prospective LCI } \\
\hline Life-time & $30 \mathrm{yr}$ & \begin{tabular}{|l|l|}
20 \\
23 \\
\end{tabular} & $\begin{array}{l}\text { Normal distribution, median: } 35 \mathrm{yr} \\
\text { Uncertainty range:[30; 40] }\end{array}$ & \begin{tabular}{|l|}
20 \\
15 \\
\end{tabular} \\
\hline Module efficiency & $11.7 \%$ & \begin{tabular}{|l|l|}
20 \\
23 \\
\end{tabular} & $\begin{array}{l}\text { Lognormal distribution, median: } 19.9 \% \\
\text { Uncertainty range:[17.7; 22.7] }\end{array}$ & \begin{tabular}{|l|}
20 \\
11 \\
\end{tabular} \\
\hline Performance ratio & $78 \%$ & [7] & $\begin{array}{l}\text { Normal distribution, median: } 83 \% \\
\text { Value given for } 2030 \text { and not for 2050, } \\
\text { without associated uncertainties }\end{array}$ & [7] \\
\hline CdTe layer thickness & $3 \mu \mathrm{m}$ & \begin{tabular}{|l|l|}
20 \\
14 \\
\end{tabular} & $\begin{array}{l}\text { Lognormal distribution, median: } 1 \mu \mathrm{m} \\
\text { Uncertainty range: }[0.1 ; 2]\end{array}$ & \begin{tabular}{|l|}
20 \\
26 \\
\end{tabular} \\
\hline $\begin{array}{l}\text { Material Utilization } \\
\text { rate }\end{array}$ & $55 \%$ & \begin{tabular}{|l|l|}
$26]$ \\
\end{tabular} & $\begin{array}{l}\text { Normal distribution, median: } 85 \% \\
\text { Uncertainty range:[70; 99] }\end{array}$ & [26] \\
\hline $\begin{array}{l}\text { Irradiation at } 37^{\circ} \mathrm{N} \text {, } \\
4^{\circ} \mathrm{W}\end{array}$ & $\begin{array}{lr}\text { MERRA } & \text { re- } \\
\text { analysis } & \\
\text { Mean } & \text { irradi- } \\
\text { ation } & 1985- \\
2013 & 2169.7 \\
\text { kWh } /\left(\mathrm{m}^{2} . \mathrm{yr}\right)\end{array}$ & 34 & $\begin{array}{l}\text { Based on projections from } 4 \text { Regional Cli- } \\
\text { mate Models (ENSEMBLES project) } \\
\text { Irradiation from MERRA for 1985-2013 } \\
+ \text { changes between } 1985-2013 \text { and } 2050- \\
2080 \text { estimated from the projections } \\
\text { based } 4 \text { regional climate models. } \\
\text { Normal distribution for changes, median: } \\
+3.3 \% \text {, } \\
\text { uncertainty range: }[+1.2 ;+5.5]\end{array}$ & 5 \\
\hline $\begin{array}{l}\text { CdTe module manu- } \\
\text { facturing origin }\end{array}$ & $\begin{array}{l}\text { Germany: } 22 \% \text {, } \\
\text { Malaysia: } 65 \% \text {, } \\
\text { USA: } 12 \%\end{array}$ & [6] &  & \\
\hline $\begin{array}{l}\text { Electricity mix of } \\
\text { manufacturing coun- } \\
\text { tries }\end{array}$ & $\begin{array}{l}\text { Data from } \\
2009\end{array}$ & [16] & $\begin{array}{l}\text { Prospective for } 2035 \\
\text { based on the "New Policies Scenario", No } \\
\text { uncertainties range is considered }\end{array}$ & [16 \\
\hline
\end{tabular}

Max Planck Institute for Meteorology in Hamburg [21, and SMHI from the Swedish Meteorological and Hydrological Institute 24. Similarly to MERRA data, monthly estimates of surface incident shortwave flux at a latitude of $37^{\circ} \mathrm{N}$ and a longitude of $5^{\circ} \mathrm{W}$ are converted into global tilted irradiation, before computing 30 years averages over the periods 1985-2015 and 2050-2080. The variation percentages between averages over these two periods ranges between $1.2 \%$ and $5.5 \%$ depending on the model, reflecting small changes of future irradiation, consistent with 33 . Note that similar values are obtained when shifting the averaging periods by \pm 5 years. This range is used as the $99 \%$ confidence interval for the variation percentage of irradiation (Case 5 of Sec. 2.2), and a normal distribution is assumed. These variations percentages are added to the 1985-2013 mean from MERRA irradiation. 


\subsection{Comparison between current and prospective global warming performances}

According to the parametrized model defined in Sec. 3.1, the current global warming performance of the considered PV system reaches $23.1 \mathrm{gCO}_{2} \mathrm{eq} / \mathrm{kWh}$ (represented by the dashed-dotted line in Fig.2). Although the parametrized performance model could be further refined, this figure is consistent with the literature 7 29.

The distribution of prospective global warming performances, obtained with future parameter values specified in Table 1 (right column), is shown in Fig 2 by the histogram. The mean value of the prospective performance distribution equals $9.8 \mathrm{gCO}_{2} \mathrm{eq} / \mathrm{kWh}$, its standard deviation is $0.77 \mathrm{gCO}_{2} \mathrm{eq} / \mathrm{kWh}$, and values range between 6.9 and $13.9 \mathrm{gCO}_{2} \mathrm{eq} / \mathrm{kWh}$. The mean value is consistent with the prospective value obtained in [7 for 2030 (equals to $10 \mathrm{gCO}_{2} \mathrm{eq} / \mathrm{kWh}$ ). These prospective performances are significantly lower than the current value, the maximum prospective value being even $40 \%$ smaller than the current performance.

The lines on the left-hand side of Fig.2 (on the left part) indicate the prospective performances obtained with median prospective values of input parameters (right column of Table 1) and for a fixed share of manufacturing countries (dashed line for the Occidental share, dotted line for the current share, and solid line for the Asian share). Not surprisingly, a higher value is obtained for the Asian share, where the electricity mix will remain mostly based on coal; and a lower value for the Occidental share, where the electricity mix will rely on more renewable energy. Given the differences between these performances, the market share seems to considerably influence the prospective performances, as will be shown and discussed in the next section.

\subsection{Identification of parameters inducing most uncertainties in the prospective environmental performance}

As described in Sec. 2.4. Sobol indices are computed to estimate the contributions of the different parameters to results' uncertainties, more precisely to the variance of the results that is induced by input parameters' uncertainties. The most important parameter is life time ( $S_{\mathrm{LT}} \sim 41 \%$ of the total variance), followed by the share of module manufacturing origin $\left(S_{\text {origin }} \sim 37 \%\right)$, efficiency $\left(S_{\eta} \sim 18 \%\right)$, and performance ratio $\left(S_{\mathrm{PR}} \sim 7 \%\right)$. Uncertainties on irradiation, CdTe layer thickness, and material utilization rate have almost no impact on the results uncertainties (their Sobol indices are smaller than 3\%). If one wants to narrow uncertainties on prospective global warming performance, uncertainties on prospective life time must be reduced as a priority.

These results also show that the share of module manufacturing origin, which is almost unpredictable at such lead time, highly contributes to the variance of the results. It is, therefore, important to take into account all conceivable possibilities for this parameter in the analysis, in order not to underestimate uncertainties on the prospective performances. Indeed, if only one possibility 


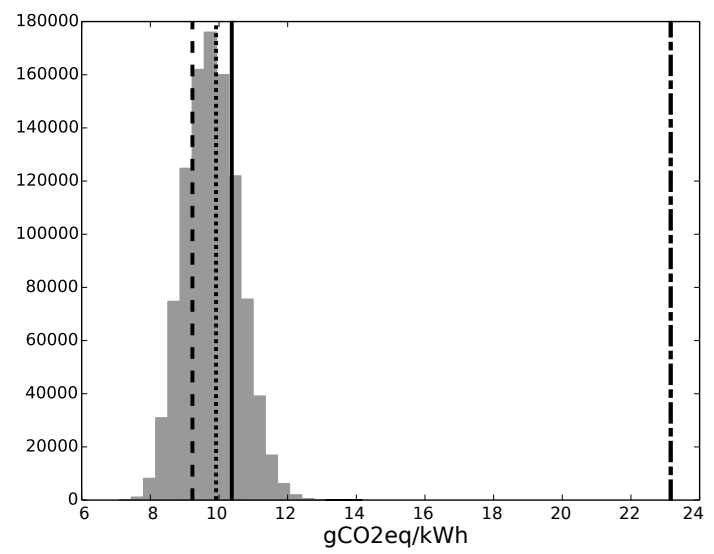

Fig. 2. Distribution of prospective global warming performances in $\mathrm{gCO}_{2} \mathrm{eq} / \mathrm{kWh}$ (histogram), calculated with input parameters specified in Table 1 (right column). The three lines on the left indicate prospective values obtained with median prospective values of input parameters and for a fixed share of manufacturing countries: $22 \%$ Germany, $12 \%$ USA, $65 \%$ Malaysia for the dotted line; $50 \%$ Germany and $50 \%$ USA for the dashed line; $50 \%$ Malaysia and 50\% China for the solid line. The current performance is indicated by the dashed-dotted line, and obtained from input parameters specified in Table 1 (left column).

for the share of module manufacturing origin is considered (e.g, the current share), the performance standard deviation drops from $0.77 \mathrm{gCO}_{2} \mathrm{eq} / \mathrm{kWh}$ to $0.61 \mathrm{gCO}_{2} \mathrm{eq} / \mathrm{kWh}$, corresponding to a decrease of $37 \%$ in the variance.

\section{Summary and discussion}

In this paper, we proposed a methodology to assess the prospective environmental performance of an electricity generation system based on renewable energy, as well as the associated uncertainties, and to identify parameters contributing the most to these uncertainties based on global sensitivity analysis. The latter need to be predicted with more accuracy in order to reduce the results' uncertainties.

Prospective LCA of electricity generation systems can be found in the literature (e.g., 7], 32]) but, to our knowledge, uncertainties are not estimated, although essential to any predictive approach. Our approach is original in considering these uncertainties and in identifying parameters contributing most to performance uncertainties.

Another original feature of this work is the combination of different types of predictions (projections of technology evolutions, climate predictions to estimate future renewable resources, and projections of market share evolution), coming from different types of scenarios, both predictive and explorative. 
The methodology was applied to the global warming performance of a residential PV panel based on CdTe technology, installed in the South of Spain and operating in 2050. We showed that performance decreases significantly compared with the current situation, from $23.1 \mathrm{gCO}_{2} \mathrm{eq} / \mathrm{kWh}$ to $9.8 \mathrm{gCO}_{2} \mathrm{eq} / \mathrm{kWh}$ on average with a standard deviation of $0.77 \mathrm{gCO}_{2} \mathrm{eq} / \mathrm{kWh}$ due to uncertainties. The latter were mostly explained by uncertainties in the life time parameter and in the share of module manufacturing origin. Uncertainties in life time should be thus reduced to narrow performance uncertainties. It is not possible to reduce uncertainties on market share, since this parameter is hardly predictable; but it shows that possible values must be considered to avoid underestimating results uncertainties.

The methodology was illustrated for a system installed at a given location, but we could easily extend the methodology to create maps of future environmental performances at any location. Indeed, irradiation values were taken from MERRA reanalysis and regional climate models, which provide spatio-temporal irradiation that can be combined to other data to obtain maps of environmental performance. Maps allow to geographically optimize installations of PV systems with other sources of energy and to know where new installations of PV systems should be prioritized. Maps of environmental performance for PV have already been produced [27, but not yet for any prospective assessment.

It should be emphasized that parameters identified as key in this methodology correspond to parameters mostly contributing to the performance variance that is induced by input parameters uncertainties. It would also be interesting to identify another type of key parameters: those whose variations between the current and future situations induce most performance changes. However, it is not an easy task, since the performance model is non-linear and changes cannot be considered as local (so that a first order Taylor expansion would not give accurate results).

Acknowledgements We are grateful to P. Padey, P. Blanc, and T. Ranchin for their useful comments. We acknowledge the Global Modeling and Assimilation Office and the GES DISC for the dissemination of MERRA reanalysis, as well as the European project ENSEMBLES for providing regional climate projections.

\section{Appendix A: Specification of the parametrized impacts model}

From Sec. 3.1 results the following parametrized impacts model for a residential PV panel based on the CdTe technology:

$$
f i(\boldsymbol{\eta}, \mathbf{e}, \mathbf{U}, \mathbf{I e l e c})=\operatorname{Iwir}+\operatorname{Iinv}+\operatorname{Isup} \cdot \frac{P}{\boldsymbol{\eta}}+\operatorname{Imod}(\mathbf{e}, \mathbf{U}, \text { Ielec }) \cdot \frac{P}{\boldsymbol{\eta}}
$$

where:

$$
\operatorname{Imod}(\mathbf{e}, \mathbf{U}, \mathbf{I e l e c})=\alpha_{1}+\beta_{1} . \text { Ielec }+\frac{\mathbf{e} \cdot \mu_{\mathrm{CdTe}}}{\mathbf{U}} . \operatorname{Icdte}(\mathbf{I e l e c})
$$




$$
\begin{aligned}
\text { Icdte }(\text { Ielec }) & =\alpha_{2}+\beta_{2} \text {.Ielec }+m_{1} \cdot\left(\alpha_{3}+\beta_{3} \cdot \text { Ielec }+m_{3} \cdot I_{T e}\right) \\
& +m_{2} \cdot\left(\alpha_{4}+\beta_{4} \cdot \text { Ielec }+m_{4} \cdot\left(\alpha_{5}+\beta_{5} . \text { Ielec }\right)\right)
\end{aligned}
$$

with:

- Ielec being the $\mathrm{gCO}_{2} \mathrm{eq} / \mathrm{MJ}$ of electricity, obtained by combining the module manufacturing origin and the electricity mix of the corresponding countries,

- Iwir, Iinv, Isup, Imod, and Icdte being the $\mathrm{gCO}_{2}$ eq of, respectively, the wiring system, the 2 inverters, $1 \mathrm{~m}^{2}$ of the buiding-integrated support, $1 \mathrm{~m}^{2}$ of module, and $1 \mathrm{~kg}$ of laminate $\mathrm{CdTe}$,

- $\alpha_{1}$ being the $\mathrm{gCO}_{2} \mathrm{eq} / \mathrm{m}^{2}$ of module without considering the electricity consumption, or the production of laminate CdTe,

- $\alpha_{2}$ being the $\mathrm{gCO}_{2} \mathrm{eq} / \mathrm{kg}$ of laminate $\mathrm{CdTe}$ without considering the electricity consumption, or the production of semicondutors $\mathrm{Cd}$ and $\mathrm{Te}$,

- $\alpha_{3}\left(\alpha_{4}\right)$ being the $\mathrm{gCO}_{2} \mathrm{eq} / \mathrm{kg}$ of semiconductor Te $(\mathrm{Cd})$ without considering the electricity consumption, or the production of $\mathrm{Te}(\mathrm{Cd})$,

- $\alpha_{5}$ being the $\mathrm{gCO}_{2} \mathrm{eq} / \mathrm{kg}$ of $\mathrm{Cd}$ without considering the electricity consumption,

- $I_{T e}$ being the $\mathrm{gCO}_{2} \mathrm{eq} / \mathrm{kg}$ of $\mathrm{Te}$,

- $\beta_{1}, \beta_{2}, \beta_{3}, \beta_{4}$, and $\beta_{5}$ being the $M J$ of electricity necessary to produce $1 \mathrm{~kg}$ of, respectively, laminate $\mathrm{CdTe}$, semiconductor $\mathrm{CdTe}$, semiconductor Te, semiconductor $\mathrm{Cd}$, and $\mathrm{Cd}$,

- $m_{1}, m_{2}, m_{3}$, and $m_{4}$ being the mass of semiconductor Te, semiconductor Cd, $\mathrm{Te}$, and $\mathrm{Cd}$ necessary to produce $1 \mathrm{~kg}$ of CdTe.

\section{Appendix B: From monthly horizontal irradiation to irradiation on inclined surfaces}

Monthly horizontal irradiation, $G_{m}$, is converted into irradiation on inclined surfaces, $G T I_{m}$, using algorithms defined in the European Solar Radiation Atlas [36. It is based on the following steps:

1. Conversion of $G_{m}$ into daily horizontal irradiation, denoted $G_{d}$, and calculation of the daily diffuse radiation $D_{d}$ from $G_{d}$ using the empirical model of Erbs et al (1982) 8].

2. Estimation of hourly global horizontal irradiation $\left(G_{h}\right)$ and hourly diffuse radiation $\left(D_{h}\right)$ from $G_{d}$ and $D_{d}$ using the relations defined in Collares-Pereira and Rabl (1979) 4 and Liu and Jordan (1960) 25], respectively. The hourly direct radiation, $B_{h}$, is then derived with: $B_{h}=G_{h}-D_{h}$.

3. Calculation of the hourly global tilted irradiation, $G T I_{h}$, as the sum of the three components: direct irradiation $B_{i}^{\text {tilted }}$, diffuse irradiation $D_{i}^{\text {tilted }}$, and reflected irradiation $R_{i}^{\text {tilted }}$. $B_{i}^{\text {tilted }}$ is obtained with a geometric relation. $D_{i}^{\text {tilted }}$ is derived using the Muneer algorithm (1990) $\left[28 . R_{i}^{\text {tilted }}\right.$ is calculated from $G_{h}$, the tilt angle, and the ground albedo (assumed equal to 0.2 ).

4. Conversion of $G T I_{h}$ into $G T I_{m}$. 


\section{References}

[1] Beloin-Saint-Pierre, D., Blanc, I.: Environmental impact of pv systems: Effects of energy sources used in production of solar panels. Proc. of the 24rd Eur. Photovoltac Solar Energy Conf., Sept. 2009, Hamburg, Germany pp. 4517-4520 (2009)

[2] Bindoff, N., et al.: Detection and attribution of climate change: from global to regional. Tech. rep. (2013), in Climate Change 2013: The Physical Science Basis. Contribution of WG I to the 5th Assessment Report of the IPCC. Link

[3] Cluzel, F., Yannou, B., Millet, D., Leroy, Y.: Exploitation scenarios in industrial system LCA. Int. J. Life Cycle Ass. 19(1), 231-245 (2014)

[4] Collares-Pereira, M., Rabl, A.: The average distribution of solar radiationcorrelations between diffuse and hemispherical and between daily and hourly insolation values. Sol. Energy 22(2), 155-164 (1979)

[5] Déqué, M., Somot, S., Sanchez-Gomez, E., Goodess, C., Jacob, D., Lenderink, G., Christensen, O.: The spread amongst ensembles regional scenarios: regional climate models, driving general circulation models and interannual variability. Clim. Dynam. 38(5-6), 951-964 (2012)

[6] Dominguez-Ramos, A., Held, M., Aldaco, R., Fischer, M., Irabien, A.: Carbon footprint assessment of photovoltaic modules manufacture scenario. In: Proc. 20th Eur. Symp. Comput. Aided Process Eng (2010)

[7] Dominguez-Ramos, A., Held, M., Aldaco, R., Fischer, M., Irabien, A.: Prospective co2 emissions from energy supplying systems: photovoltaic systems and conventional grid within spanish frame conditions. Int. J. Life Cycle Ass. 15(6), 557-566 (2010)

[8] Erbs, D., Klein, S., Duffie, J.: Estimation of the diffuse radiation fraction for hourly, daily and monthly-average global radiation. Sol. energy 28(4), 293-302 (1982)

[9] Frischknecht, R., et al.: The ecoinvent database: Overview and methodological framework (7 pp). Int. J. Life Cycle Ass. 10(1), 3-9 (2005)

[10] Fthenakis, V., Frischknecht, R., Raugei, M., Kim, H.C., Alsema, E., Held, M., de Wild-Scholten, M.: Methodology guidelines on life cycle assessment of photovoltaic electricity. Tech. rep., IEA-PVPS Task 12 (2011)

[11] Garabedian, R.: First solar technology update. Tech. rep., First solar Inc. (2013)

[12] Heijungs, R., Huijbregts, M.: A review of approaches to treat uncertainty in lca. Orlando, Fla.: Elsevier (2004)

[13] Heijungs, R., Frischknecht, R.: Representing statistical distributions for uncertain parameters in lca. relationships between mathematical forms, their representation in ecospold, and their representation in cmlca (7 pp). Int. J. Life Cycle Ass. 10(4), 248-254 (2005)

[14] Houari, Y., Speirs, J., Candelise, C., Gross, R.: A system dynamics model of tellurium availability for cdte pv. Prog. in Photovoltaics 22(1), 129-146 (2014)

[15] IEA: Technology roadmap: solar photovoltaic energy. Tech. rep., International Energy Agency (2010), Link

[16] IEA: World energy outlook. Tech. rep. (2011), link

[17] IEA: $\mathrm{CO}_{2}$ emissions from fuel combustion, highlights. Tech. rep. (2013), link

[18] IEA: Key world energy statistics 2013. Tech. rep. (2013), Link

[19] IPCC: Climate change 2007. ipcc fourth assessment report. the physical science basis. Tech. rep. (2007), Link

[20] Itten, R., Wyss, F., Frischknecht, R.: Lci of the global crystalline photovoltaics supply chain and of future photovoltaics electricity production. Tech. rep., Treeze Ltd, Uster, Switzerland (2014) 
[21] Jacob, D.: A note to the simulation of the annual and inter-annual variability of the water budget over the baltic sea drainage basin. Meteorol. Atmos. Phys. $77(1-4), 61-73$ (2001)

[22] Jones, C.G., Willén, U., Ullerstig, A., Hansson, U.: The rossby centre regional atmospheric climate model part i: model climatology and performance for the present climate over europe. AMBIO 33(4), 199-210 (2004)

[23] Jungbluth, N., Stucki, M., Flury, K., Frischknecht, R., Büsser, S.: Life cycle inventories of photovoltaics. ESU-services Ltd., Uster, CH (2012)

[24] Kjellström, E., Bärring, L., Gollvik, S., Hansson, U., Jones, C.: A 140-year simulation of european climate with the new version of the rossby centre regional atmospheric climate model (rca3). SMHI reports meteorology and climatology 108 (2005)

[25] Liu, B.Y., Jordan, R.C.: The interrelationship and characteristic distribution of direct, diffuse and total solar radiation. Solar Energy 4(3), 1-19 (1960)

[26] Marwede, M., Reller, A.: Future recycling flows of tellurium from cadmium telluride photovoltaic waste. Resources, Conservation and Recycling 69, 35-49 (2012)

[27] Ménard, L., et al.: Benefit of geoss interoperability in assessment of environmental impacts illustrated by the case of photovoltaic systems. Selected Topics in Applied Earth Observations and Remote Sensing, IEEE Journal of 5(6), 1722-1728 (2012)

[28] Muneer, T.: Solar radiation model for europe. Build. Serv. Eng. Res. T. 11(4), $153-163(1990)$

[29] Nugent, D., Sovacool, B.: Assessing the lifecycle greenhouse gas emissions from solar pv and wind energy: A critical meta-survey. Energ. Policy 65, 229-244 (2014)

[30] Padey, P., Girard, R., le Boulch, D., Blanc, I.: From lcas to simplified models: A generic methodology applied to wind power electricity. Environ. Sci. Technol. 47(3), 1231-1238 (2013)

[31] Pesonen, H.L., et al.: Framework for scenario development in lca. Int. J. Life Cycle Ass. 5(1), 21-30 (2000)

[32] Raugei, M., Frankl, P.: Life cycle impacts and costs of photovoltaic systems: current state of the art and future outlooks. Energy 34(3), 392-399 (2009)

[33] Remund, J., Müller, S.C.: Trends in global radiation between 1950 and 2100. In: 10th EMS Annual Meeting, 10th European Conference on Applications of Meteorology (ECAM) Abstracts, held Sept. pp. 13-17 (2010)

[34] Rienecker, M.M., et al.: Merra: Nasa"s modern-era retrospective analysis for research and applications. J. Climate 24(14) (2011)

[35] Saltelli, A.: Making best use of model evaluations to compute sensitivity indices. Computer Physics Communications 145(2), 280-297 (2002)

[36] Scharmer, K., Greif, J.: The European solar radiation atlas, vol. 2. Presses des MINES (2000)

[37] Sobol', I.: Sensitivity Estimates for Nonlinear Models. Mathematical Modeling and Computational Experiment 1(4), 407-414 (1993)

[38] Stainforth, D.A., et al.: Uncertainty in predictions of the climate response to rising levels of greenhouse gases. Nature 433(7024), 403-406 (2005)

[39] Van Meijgaard, E., Van Ulft, L., Van de Berg, W., Bosveld, F., Van den Hurk, B., Lenderink, G., Siebesma, A.: The knmi regional atmospheric climate model racmo version 2.1. Tech. rep. (2008)

[40] Weidema, B.P., Wesnæs, M.S.: Data quality management for life cycle inventoriesan example of using data quality indicators. Journal of Cleaner Production 4(3), 167-174 (1996) 